\title{
Uncrossed and Crossed Inhibition in the Inferior Colliculus of the Cat: A Combined 2-Deoxyglucose and Electrophysiological Study ${ }^{1}$
}

\author{
W. R. WEBSTER, ${ }^{2}$ J. SERVIERE, ${ }^{3}$ R. MARTIN, AND M. BROWN \\ Neuropsychology Laboratory, Department of Psychology, Monash University, Clayton, Victoria, Australia 3168
}

\begin{abstract}
The cat inferior colliculus (IC) was studied with 2-deoxyglucose (2-DG). By presenting high-frequency tone bursts to one ear and white noise bursts simultaneously to the other, a band of reduced or inhibitory labeling was revealed in the central nucleus (ICC) of the IC ipsilateral to the ear receiving the tone bursts. It was concluded that this ipsilateral inhibition might be related to the organization of excitatory/inhibitory units in ICC. In the opposite ICC, narrow bands of increased labeling were seen. In some animals, the positions of single units were marked, and tone frequencies were presented under 2-DG, which were the same as these units' characteristic frequencies (CFs). The positions of the units coincided with the position of the inhibitory bands, indicating that they were functional isofrequency-inhibitory contours. Unlike higher auditory centers, the binaural inhibitory areas were in register with and not orthogonal to the excitatory isofrequency contours. The inhibitory contours were generally larger than the excitatory contours and became even larger in more caudal sections. Both the inhibitory and excitatory contours extended into dorsal cortex areas of IC. In two other cats, high-frequency tone bursts and white noise bursts were presented to the same ear, and both a band of increased and a band of reduced labelling were found in the IC contralateral to this ear. The inhibitory band was always lateral to the excitatory band and was often smaller. They did not become larger in more caudal sections. The position of a unit in one cat was marked by pontamine sky blue, and the position of the unit coincided with the position of the excitatory band. It was concluded that this lateral inhibitory band represents high-frequency inhibitory sidebands of cells with CFs lower than the stimulating tone. It is concluded that the 2-DG method might reveal hitherto unknown inhibitory systems if stimuli could be combined with diffuse stimuli that raised the general background activity of sensory systems.
\end{abstract}

The auditory cortex (A1) of the cat has been shown to be

Received July 23, 1984; Revised December 3, 1984;

Accepted January 14, 1985

\footnotetext{
${ }^{1}$ This work was supported by grants from the National Health and Medical Research Council of Australia and the Australian Research Grants Scheme. J. S. was supported by a Monash University Research Fellowship. We wish to thank Mr. Richard Newman for the design, construction, and programming of the image analysis system, Mr. Craig Miller for additional programming, Mr. V. Kohout for photography, and Mrs. E. Hartley for histological assistance. We wish also to thank Professor R. H. Day for his encouragement and supporl and Dr. C. Batini for her critical reading of the manuscript.

${ }^{2}$ To whom correspondence should be addressed.

${ }^{3}$ Current address: Laboratoire de Psychophysiologie Sensorielle, Université de Paris, VI, 9, Quai St. Bernard, Paris 75005, France.
}

organized into areas containing different types of binaural cells. There are some areas containing cells which respond best to stimulation of both ears or are excited monaurally by both ears (E/E cells) and other areas containing neurons excited by the contralateral ear and inhibited by the ipsilateral ear ( $E / l$ cells) (Imig and Adrian, 1977; Imig and Brugge, 1978; Middlebrooks et al., 1980; Imig and Reale, 1981). These bands are organized rostrocaudally in A1 and are orthogonal to the isofrequency contours. Retrograde labeling studies have shown that these bands connect with segregated areas of the ventral division ( $V$ ) of the medial geniculate body, which are also organized rostrocaudally and orthogonal to the isofrequency contours (Middlebrooks and Zook, 1983). While physiological studies of $V$ have failed to find such a binaural organization (Calford and Webster, 1981), this failure could be a function of the complex folded structure of the isofrequency contours (Calford and Webster, 1981; Middlebrooks and Zook, 1983).

The central nucleus of the inferior colliculus (ICC) of the cat projects to V, but Semple and Aitkin (1979) have found no segregation between $E / /$ and $E / E$ units in $I C C$, suggesting that the binaural organization of ICC might differ from the higher parts of the auditory pathway. The frequency organization of ICC has been extensively studied with a combined $2 \cdot\left[{ }^{14} \mathrm{C}\right]$ deoxyglucose (2-DG), electrophysiological, and horseradish peroxidase study (Servière et al., 1984). The general organization of functional isofrequency contours appears to match largely the laminae of the Golgi model of ICC put forward by Oliver and Morest (1984), except that the isofrequency contours are orthogonal to the proposed laminae in their lateral division of ICC. They appear to extend well into what Oliver and Morest (1984) have defined as unlaminaled areas of inferior colliculus (IC), the dorsal cortex (DC) and the dorsomedial nucleus (DM) (Servière et al., 1984). Although the 2-DG technique has clearly shown contralateral excitatory contours which could represent $E / l$ and $E / E$ effects, it did not appear to be capable of revealing any specific ipsilateral inhibitory effects in ICC. Experiments in which only the contralateral ear was stimulated or in which an interaural intensity difference (IID) was employed failed to produce evidence of unequivocal inhibitory effects in either ICC (Servière et al., 1984). This failure could be due to several possibilities. For example, the presence of a considerable number of $E / E$ and $E / O$ cells might not allow small reductions in the amount of label to be detected. Also, the level of spontaneous activity in ICC in these experiments might not allow sufficient background activity for a reduction in label to be detected, as only $50 \%$ of units recorded under barbiturate have spontaneous activity compared with most units recorded in the awake cat (Bock and Webster, 1974a, b).

In the visual system, Bishop et al. (1973) were able to reveal nondominant ipsilateral inhibitory effects in apparently monocular units without spontaneous activity. In these studies, random stimuli (relative to computer response histograms) were presented to the excitatory or contralateral eye to produce a nonspecific increase in the firing rate of cells. When appropriate time locked stimuli were presented to the ipsilateral eye, then the computer response histo- 
grams showed clear inhibitory effects. To test our hypothesis concerning a lack of spontaneous activity, we adapted this general technique by presenting white noise bursts to one ear to raise the general activity in ICC. Simultaneously, tone bursts were presented to the other ear to see whether the increased activity could be suppressed or inhibited. We hoped that this technique would reveal either an ipsilateral or uncrossed inhibitory organization or perhaps even an $\mathrm{E} / \mathrm{l}$ organization in high-frequency regions of ICC.

Forms of inhibition other than uncrossed inhibition have been reported in ICC. Many cells have inhibitory sidebands from contralateral monaural stimulation, and some have completely inhibitory response areas. The absolute percentage of such cells in ICC is not known (Aitkin et al., 1975; Semple and Aitkin, 1979). It was decided to use a similar experimental paradigm and test for crossed or contralateral inhibition by presenting both white noise and tones to the same ear. While there are complications in this procedure related to masking at the periphery, we predicted that we would still be able to detect bands of reduced labeling. In both the uncrossed and the crossed experiments, electrophysiological recordings were taken from some animals to determine the relationship between any inhibitory effects and the isofrequency excitatory contours found in ICC with 2-DG (Servière et al., 1984). A preliminary report of the first experiments on uncrossed inhibition has been presented (Webster et al., 1984b).

\section{Materials and Methods}

Surgery and electrophysiological procedures. Young adult cats (16 to 20 weeks old) weighing from 0.9 to $2.0 \mathrm{~kg}$ were anesthetized with pentobarbita sodium (Nembutal, $45 \mathrm{mg} / \mathrm{kg}$ ). Tracheal and venous cannulae were inserted. Each animal was placed in an electrically shielded, soundproofed room (greater than $70 \mathrm{~dB}$ sound pressure level (SPL) attenuation, $250 \mathrm{~Hz}$ to 8.0 $\mathrm{kH} z$ ). The ear bars were removed after the head was held by two threaded brass posts attached to the skull with dental acrylic and stainless stee screws. Both pinnae were then removed, and a recording electrode was placed on each round window to measure and monitor the sensitivity of the cochlea.

In animals from which electrophysiological recordings were made, a craniotomy was performed to expose the IC on one side by aspiration of the overlying cortex. In these animals, pontamine sky blue was injected by iontophoresis from a recording pipette ( $5 \mu \mathrm{A}$ for $20 \mathrm{~min}$ electrode negative) at a position of a single unit in ICC with a certain $\mathrm{CF}$. The CF of this unit was then employed as the stimulating tone frequency during a $45 \cdot \mathrm{min}$ period after injection of 2-DG

Sound system. A stimulating system incorporating a probe microphone and a Beyer DT48 transducer was sealed close to the tympanum. The sound pressure at the tympanum was calibrated on line with a NOVA 2 computer using methods already described (Calford and Webster, 1981). The resulting calibration table resided in computer memory to allow both manual and computer-controlled intensity settings. Tuning curves for single units were obtained either manually or under computer control acting through interfaces to a digital oscillator (Wavetek, model 159) and to digital attenuators (Grason and Stadler, model 1284). The duration of tone bursts were controlled by a Devices Digitimer which was triggered by the computer. The tone bursts were shaped by electronic switches set to have 5 -msec rise and fall times, and stimuli to each ear were gated to commence at a zero crossing point at the same time. For animals receiving one tone stimuli, $250-\mathrm{msec}$ tone bursts were presented at an overall rate of $2 / \mathrm{sec}$. For animals receiving two tone stimuli, each frequency was presented alternately at an overall rate of $1 / \mathrm{sec}$ with $250 \mathrm{msec}$ of silence between each consecutive tone burst. Both stimulus frequency and intensity as well as rate of alternation were controlled by the computer. The level of white noise was measured with a $1 / 4$-inch microphone (B \& K 4135) coupled $1 \mathrm{~mm}$ from the stimulating probe. A graphic equalizer was used to compensate for the output of the transducers in conjunction with a wave analyser making the white noise flat in octaves from 250 to $16,000 \mathrm{~Hz}$. Higher frequencies could not be compensated for by this method The intensity settings for octave bands was noted for each overall white noise intensity. When tones and white noise were presented to the same ear, the electrical signals were passed through a mixer

Recording system. Micropipettes containing a saturated solution of pontamine sky blue in $2 \mathrm{M} \mathrm{NaCl}$ (impedance, 2 to 6 megohms) were advanced into the $\mathrm{IC}$ by a stepping motor controlled from outside the soundproof room Characteristic frequencies were obtained for units along each electrode track, and poststimulus histograms (PSTs) were also obtained on-line under computer control. Where appropriate, the binaural interaction pattern of units was determined. Both spike and stimulus event times were stored by the computer on digital tape allowing off-line analysis of PSTs and off-line plotting using a digital plotter (Servigor, model 281). On-line PSTs could be also obtained on the computer's printer

$2-\left[{ }^{14} \mathrm{C}\right]$ deoxyglucose procedures. All animals were injected with a pulse of 2-DG (200 $\mu \mathrm{Ci} / \mathrm{kg}$; specific activity, $56.6 \mathrm{mCi} / \mathrm{mmol}$; Amersham/Searle Corp.). After 45 min of auditory stimulation, each animal was killed by an overdose of anesthetic, and the brains were quickly removed and frozen at $-45^{\circ} \mathrm{C}$. Transverse brain sections $(20 \mu \mathrm{m})$ were cut on a cryostat (Minotome IEC) at $-20^{\circ} \mathrm{C}$, picked up on numbered slides, and dried on a hotplate at $60^{\circ} \mathrm{C}$. Autoradiographs were prepared by exposing the sections to $x$-ray film (SB5 Kodak) for 7 days or to mammography (DuPont) for 14 days. While sectioning the brains of the animals used for physiological recordings, the position of a blue spot in any section was noted and traced before autoradiography. After autoradiography, all sections were stained using a Niss technique, except for those sections containing a blue spot. These sections were stained with neutral red to facilitate detection of the blue spot. The blue spot produced by pontamine sky blue can be quite small (2 to $40 \mu \mathrm{m}$ ) (Boakes et al., 1974; Lee et al., 1969). While the spots can be readily detected in sections stained with neutral red, they are difficult to see in black and white photographs. We have therefore indicated in figures the position of a blue spot by a small circle.

The 2-DG autoradiographs were analyzed by a computer image processing system similar to one reported by Gallistel et al. (1982). The 2-DG sections were exposed along with 2-DG standards (Amersham set 632), and the system provided a "semiquantitative" method of measuring the autoradiographs (Gallistel et al., 1982). The measurements allowed the determination of ordinal positions in monotonic tunctions relating auditory function to both optical density and the level of 2-DG uptake as indicated by the standards. The method lacks the power of the fully quantitative system of Sokoloff (Goochee et al., 1980), but it provides sufficient quantitative information to allow judgments of whether an area contained significantly greater labeling than a critical area from the same animal.

A standard area could be specified on the computed image as an overlay in the form of a rectangle. This rectangle could be adjusted to fit into any desired arca or band and could be placed anywhere on the autoradiograph by cursor control. This procedure allowed measurements and comparisons of optical density within equal areas of the autoradiograph. Each autoradiograph was scanned using a color-coded display of optical density. From these displays, it was generally easy to categorize areas of $\mathrm{IC}$ and nonauditory brainstem into excitatory areas, inhibitory areas, and "nonresponsive" areas. In most cases, similar judgements could be made directly from the autoradiograph by visual inspection using a microfilm reader (Carl Zeiss, model DL II). Measurements of the width of any selective area were made on the microfilm reader at magnification $\times 17.5$ calibrated with a stage micrometer. The measurements of some inhibitory areas or bands was often difficult, particularly when low intensities were employed. In these cases, multiple readings were made, and a mean width was calculated.

Both excitatory and inhibitory areas were compared with background control areas. In the case of inhibitory areas, two comparisons were made: (1) with an area of the ICC adjacent to the band of reduced labeling, which allowed us to determine whether the tone bursts were reducing the activity produced by white noise; and (2) with an area of nonauditory brain stem just below the relevant ICC. We hoped this method would give us some measure of general level of uptake of label. While this is a weaker criterion than that obtained with the fully quantitative method of Sokoloff, it did prove to be a consistent comparison, as the brainstem areas were rather uniformly labeled in each animal. We did not use a comparison of gray with white matter (Sharp et al., 1983), as we wished to make all comparisons in the same autoradiograph. Our general technique does not permit valid comparisons of optical density across animals.

Statistical analysis. The densitometric measurements were analyzed statistically using a $t$ test of the difference scores in optical density between areas. The degrees of freedom represent the number of pixels minus one. Although we could predict the approximate position of any excitatory band from our previous research (Servière et al., 1984), the determination of any inhibitory effects was essentially a posteriori. In addition, we carried out a multiple $t$ test on each animal. To control for both of these factors, the statistical data were recalculated using Scheffé's criterion (Winer, 1970), which provides an $\alpha$-rate for tests of all possible comparisons to be made a posteriori. Since the $\alpha$-values stit exceded 0.01 for this conservative test, the standard $t$ values were reported.

Stimulus paradigms. Ten young cats were run under various control and 
experimental conditions. A summary of the experimental designs and stimulus conditions is set out in Table

\section{Results}

Control experiments. Four control animals were tested. The first animal received no auditory stimulus in either ear. There were no signs of any areas of increased or decreased selective marking in the autoradiographs (Fig. 1). The level of uptake in the left ICC was higher than background in the brain stem (Table II). Similar rosults were found for the right ICC. The second control animal received 60 $\mathrm{dB}$ white noise in the left ear and no stimulus in the right. The amount of labeling in the right ICC was significantly greater than both background and the opposite ICC (Table II). A montage of the ICC of this control animal showed a diffuse increase in labeling throughout ICC (Fig. 2). As expected from the characteristics of the white noise, less labeling was apparent in the more medial or very highfrequency regions of ICC (Fig. 2). Although the method did not allow a strict comparison between the individual animals, the amount of label produced by the white noise is greater than that apparent in the no-stimulus control (Table II).

In the other two control animals, the amount of label in the ICC contralateral to the ear receiving the white noise was also greater than the amount of label in both the background and in the opposite ICC (Table II). The important point to be stressed, however, is that in none of the control animals was there any sign of selective bands of labeling, either in the form of an increase or a decrease in the amount of label.

Uncrossed inhibition experiments without physiological recordings. In animal 5 , tone bursts of $80 \mathrm{~dB} \mathrm{SPL}$ and $15.0 \mathrm{kHz}$ were presented to the left ear, and $60 \mathrm{~dB}$ bursts of white noise were presented to the right ear. The tone bursts presented to the left ear have produced a sharp band of increased labeling in the contralateral ICC, which is very similar to the bands produced previously (Servière et al., 1984). By contrast, in the ICC ipsilateral to the ear receiving the tone, there was a clear band of reduced labeling (Fig. 3) which was in register with the excitatory band. It contained significantly less label than in the areas surrounding it but significantly more label than the background area (Table III; Fig. 3). In general, the width of this band of reduced label was larger than the excitatory band (580 versus $330 \mu \mathrm{m}$ ). They both tended to get larger in more caudal sections (Fig. 3, $E$ versus $B$ ) (660 versus $580 \mu \mathrm{m}$ ). Although it is extremely difficult to define the extert of ICC in Nissl sections, the excitatory and the inhibitory or reduced bands extend outside ICC as defined in Golgi sections by Oliver and Morest (1984) into lower levels of DC and DM.

In animal 6, 50-dB tones of two frequencies (8.5 and $15.9 \mathrm{kHz}$ ) were presented to the right ear, while white noise bursts of $60 \mathrm{~dB}$ were presented to the left ear. In this instance and in other experiments involving two frequencies given to one ear, the frequencies were alternated, which means that each frequency was presented at $1 / \mathrm{sec}$ or only half the number of times as when a single frequency was given to an animal. In ICC opposite to the ear receiving the tones, there were two very sharp excitatory bands produced by the tones (Fig. 4). A lateral band was produced by $8.5 \mathrm{kHz}$ tones and a ventral and medial band by $15.9 \mathrm{kHz}$ tones, as would be predicted from our earlier work (Servière et al., 1984). These bands were quite narrow (200 to $250 \mu \mathrm{m}, 8.5 \mathrm{kHz}$ and 300 to $350 \mu \mathrm{m}, 15.9 \mathrm{kHz}$ ), probably reflecting the lower intensity and/or the smaller number of stimuli presented at each frequency. The tones have also produced two less pronounced bands of reduced labeling in the ICC ipsilateral to the ear receiving the tones. These inhibitory bands contained less label than the surrounding areas of ICC but again contain more label than the background (Table III). The bands of reduced labeling were much wider ( 300 to $350 \mu \mathrm{m}, 8.5 \mathrm{kHz}$ and $400 \mu \mathrm{m}, 15.9 \mathrm{kHz}$ ) than the excitatory bands noted above in Figure $4 B$. The reductions in labeling were not as clearly distinguishable as those in Figure 3 , probably reflecting the difference in intensity and rate of presentation. However, they were quite discernable in Figure $4, B$ and $C$. They also appeared to become larger in more caudal sections $(400$ $\mu \mathrm{m}, 8.5 \mathrm{kHz}$ and $450 \mu \mathrm{m}, 15.9 \mathrm{kHz}$ ) (Fig. 4, E versus B). Although they were larger, the inhibitory bands did appear to be in quite good relative register with the excitatory bands in the opposite ICC. Thus, it might be concluded from our earlier work (Servière et al., 1984) that the more dorsal and lateral inhibitory bands have been produced by $8.5-\mathrm{kHz}$ tones and the more ventral and medial by $15.9-\mathrm{kHz}$ tones. Both the excitatory and the inhibitory bands remained in register through the rostrocaudal extent of ICC and, in more caudal sections (Fig. 4, $B$ and $C$ ), they appeared to extend into regions outside ICC (Oliver and Morest, 1984).

Uncrossed inhibition experiments with physiological recordings. Although the bands of reduced or inhibited labeling appeared to be in reasonable register with the excitatory bands in the opposite ICC, the width of the bands, sometimes extending laterally and sometimes extending medially, made us hesitant to conclude that they were isofrequency inhibitory bands. To test this proposition, single unit recordings were made from the $I C C$ contralateral to the ear to which white noise bursts would be given under 2-DG. In animal 7, a recording track was made consisting of 25 units. A tonotopic sequence was obtained in which the value of the CF for units progressively increased with increasing depth of penetration. The position of two units with CFs of 9.0 and $17.0 \mathrm{kHz}$, respectively, was marked by the extrusion of pontamine sky blue. These two frequencies were then presented to the ear ipsilateral to the ICC in which the spots were deposited (Fig. 5).

Tone bursts of $80 \mathrm{~dB}$ SPL at 9.0 and $17.0 \mathrm{kHz}$ paired with $60 \mathrm{~dB}$ SPL white noise bursts have produced two sharp bands of increased labeling in the contralateral ICC $(9.0 \mathrm{kHz}, 230$ to $330 \mu \mathrm{m} ; 17.0 \mathrm{kHz}$, 200 to $300 \mu \mathrm{m})$. They have also produced two significant bands of

TABLE I

Summary of stimulus paradigms and conditions

\begin{tabular}{|c|c|c|c|c|}
\hline $\begin{array}{l}\text { Animal } \\
\text { No. }\end{array}$ & Paradigm & Left Ear & Right Ear & Electrophysiology \\
\hline 2 & $W^{a}{ }^{a}$ control & $W N(60 \mathrm{~dB})$ & No stimulus & No \\
\hline 4 & WN control & $W N(80 \mathrm{~dB})$ & No stimulus & No \\
\hline 5 & Uncrossed inhibition & $15.0 \mathrm{kHz}(80 \mathrm{~dB})$ & $W N(60 \mathrm{~dB})$ & No \\
\hline 6 & Uncrossed inhibition & $\mathrm{WN}(60 \mathrm{~dB})$ & 8.5 and $15.9 \mathrm{kHz}(50 \mathrm{~dB})$ & No \\
\hline 9 & Crossed inhibition & $\begin{array}{c}18.0 \mathrm{kHz}(80 \mathrm{~dB}) \\
W N(50 \mathrm{~dB})\end{array}$ & No stimulus & No \\
\hline 10 & Crossed inhibition & $\begin{array}{c}9.2 \mathrm{kHz}(80 \mathrm{~dB}) \\
W N(80 \mathrm{~dB})\end{array}$ & No stimulus & Yes \\
\hline
\end{tabular}

${ }^{a}$ WN, white noise. 
A

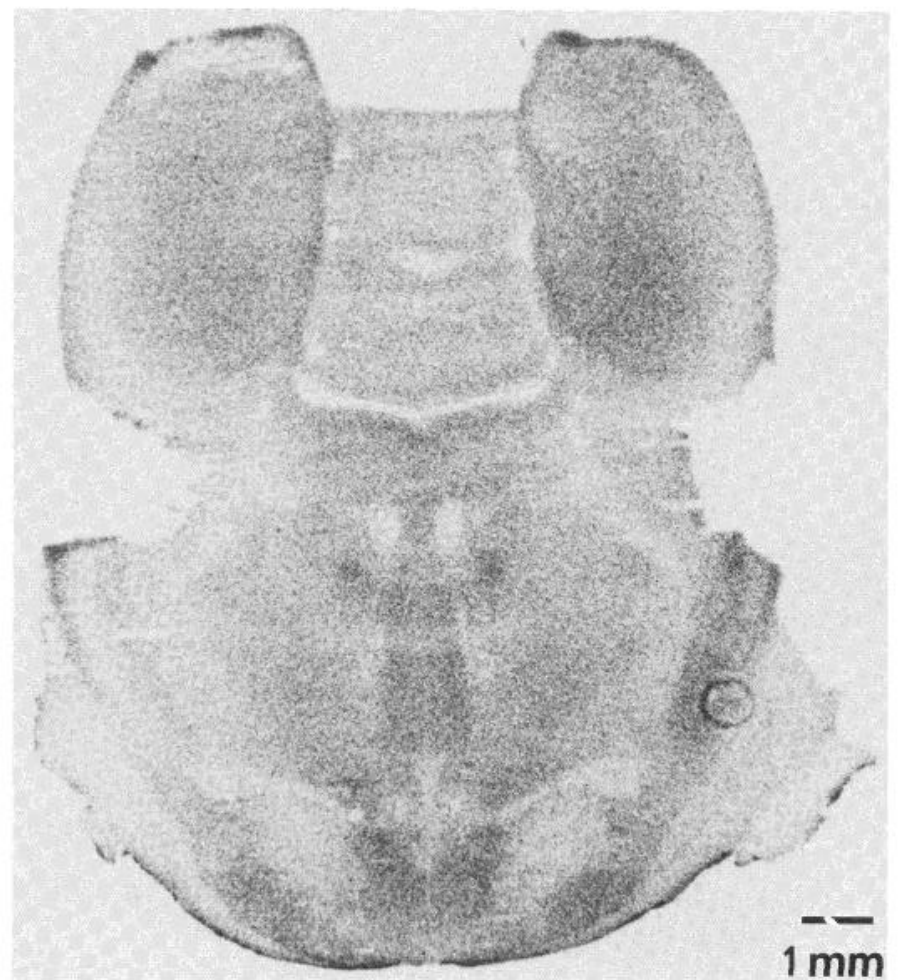

B

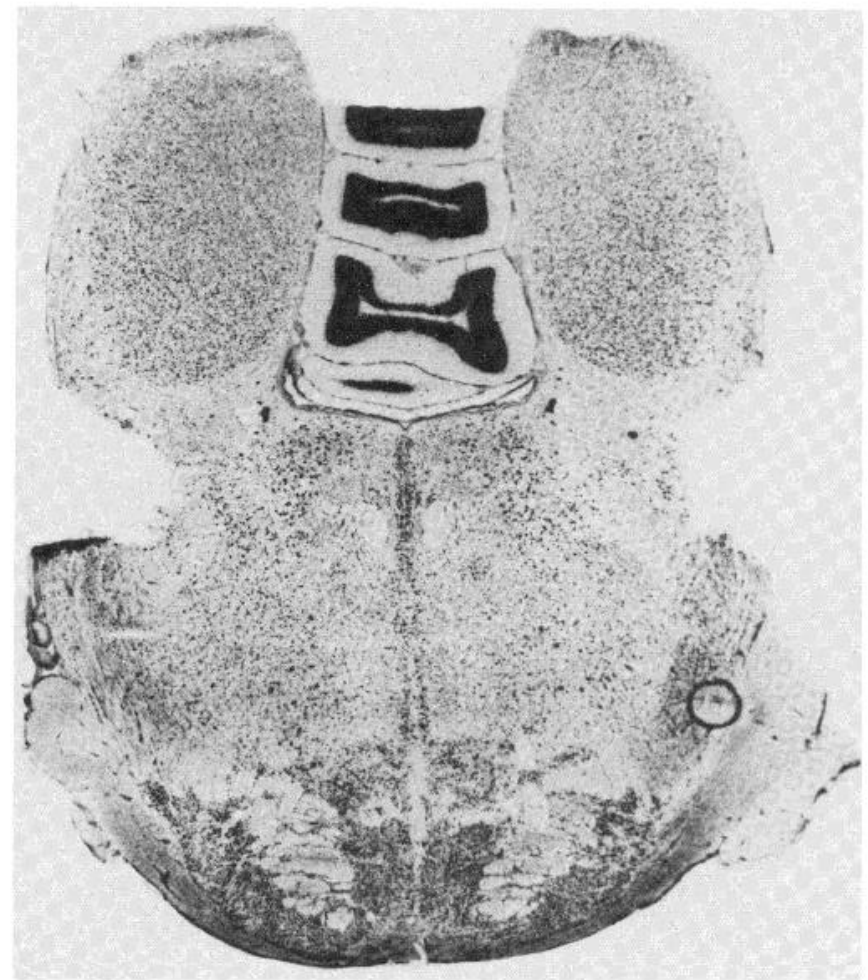

Figure 1. An autoradiograph $(A)$ and a photomicrograph of a Nissl stain of the same section $(B)$ showing both ICs in animal 1 (control). This animal received no auditory stimulation, and neither IC contains any signs of selective 2-DG labeling.

TABLE ॥

Control animals

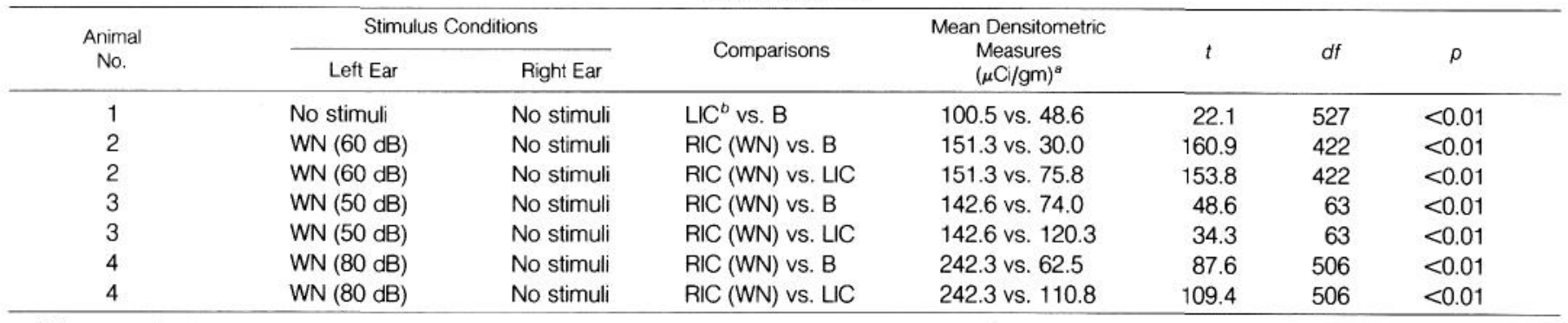

${ }^{a}$ Tissue equivalence was calculated by an equation relating pixel grayscale to the exposed standards, which came provided with a calibration based on Sokoloff's data (1977).

${ }^{\circ}$ LIC or RIC, left or right inferior colliculus; B, background, defined as a nonauditory area of the brainstem; WN, white noise.

reduced labeling in the other ICC (Table IV; Fig. 5). However, the band of reduced labeling to $9.0 \mathrm{kHz}$ was not clearly defined, although it contained statistically less label than surrounding areas. The position of the blue spots coincided with the position of the inhibitory bands, and we would infer from our previous work (Servière et al., 1984) that these were isofrequency inhibitory contours. The reduced bands, particularly to the higher tone, appeared again to become broader in more caudal sections $(350 \mu \mathrm{m}$ rostrally to $600 \mu \mathrm{m}$ caudally). The areas which were not inhibited in ICC contralateral to the white noise bursts contained as much label $(159.3 \mu \mathrm{Ci} / \mathrm{g})$ as the excitatory bands. This high level of labeling probably reflected the fact that the white noise bursts were presented on each trial, whereas the tones were alternated. In more caudal sections, both excitatory and inhibitory contours appeared to extend outside ICC (Oliver and Morest, 1984).

All of the units recorded along the track were sharply tuned, except for the second and third units which had CFs of 7.0 and 8.0 $\mathrm{kHz}$, respectively. These two units were very sensitive over a broad range $(1.0$ to $12.0 \mathrm{kHz})$ and were probably located outside ICC. Thresholds for all the cells were also very sensitive and ranged from $-10 \mathrm{~dB}$ to $20 \mathrm{~dB}$. The cell marked with the $\mathrm{CF}$ of $17.0 \mathrm{kHz}$ was also a clear $\mathrm{E} / \mathrm{l}$ cell, but the $9.0 \mathrm{kHz}$ cell was an $\mathrm{E} / \mathrm{O}$ cell with a lowfrequency inhibitory sideband. Of the 25 units, 5 were $E / l$ units, 2 were $I / E$ (contralateral inhibited, ipsilateral excitatory), 4 were $E / E$, and 12 were $E / O$. The remaining 2 cells consisted of an $O / E$ (ipsilateral monaural), which was also interaurally time sensitive and an $\mathrm{O} / \mathrm{O}(\mathrm{F})$ cell which was facilitated by only firing to binaural stimuli.

In animal 8, electrophysiological recordings were also taken before testing for binaural inhibition (Figure 6). The right ear received $80-\mathrm{dB}$ tone bursts at $10.5 \mathrm{kHz}$, and the left received $80-\mathrm{dB}$ white noise bursts. The tone bursts have produced a clear excitatory band (250 $\mu \mathrm{m})$ in the left ICC and a clear band of reduced labeling in the 
Webster et al.
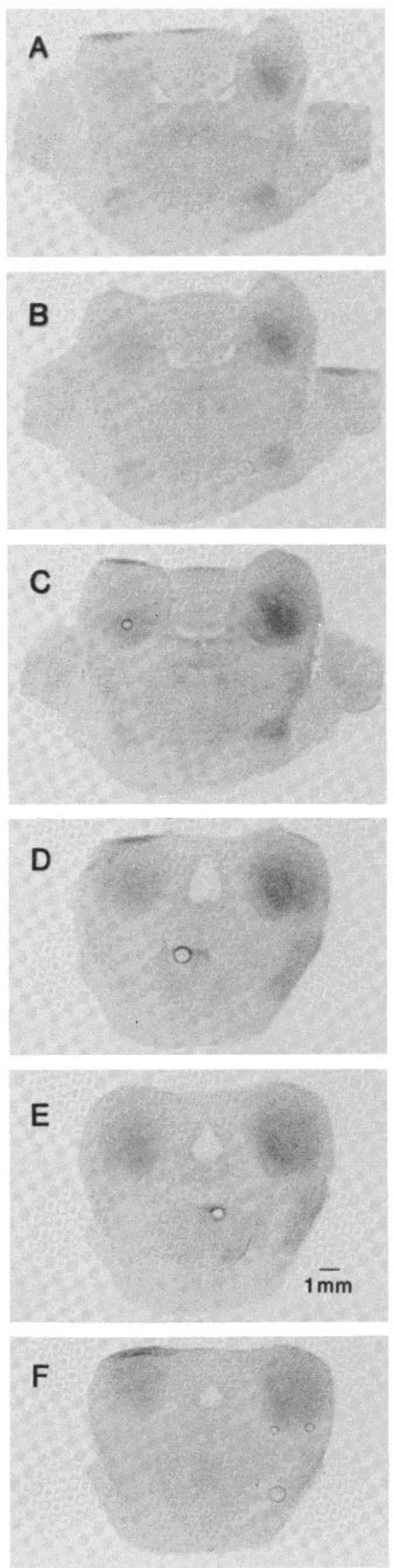

Vol. 5, No. 7, July 1985
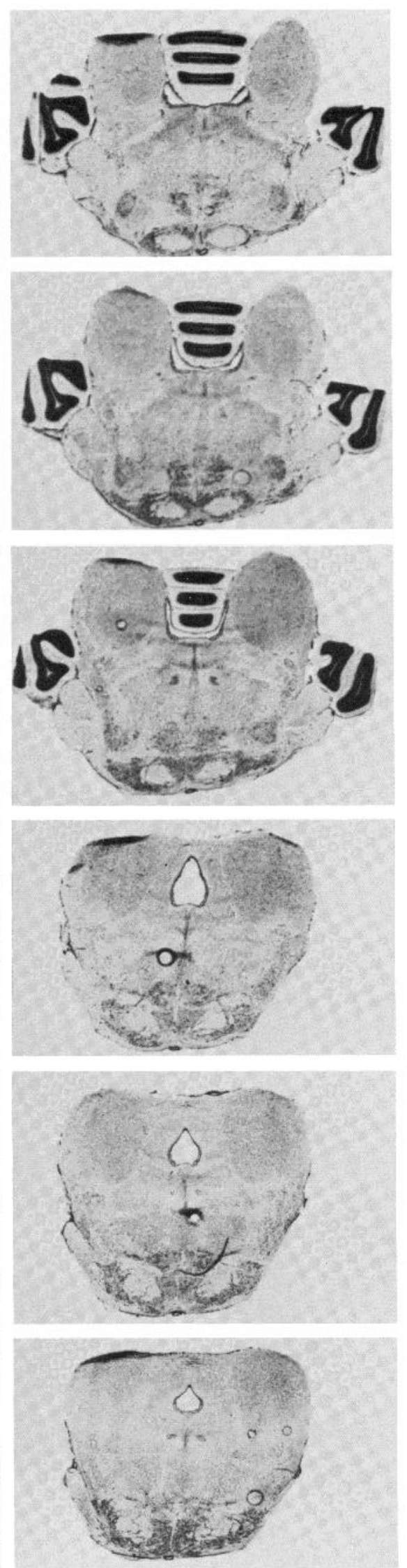

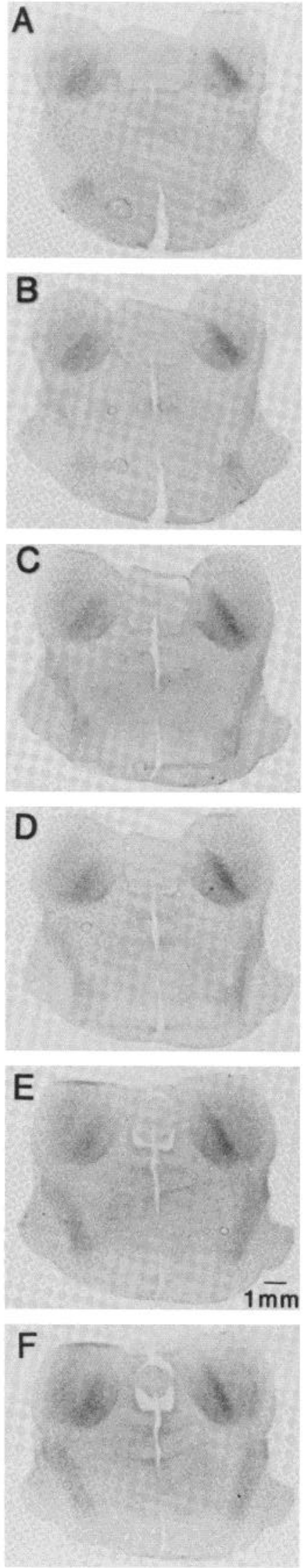
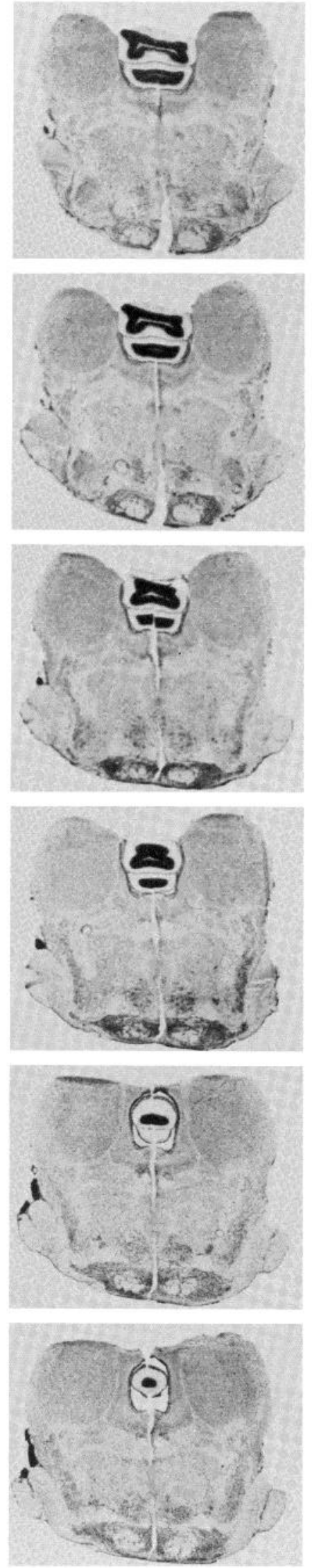

opposite ICC (300 $\mu \mathrm{m})$ (Fig. 6, A and B). Two electrode penetrations were made in this animal. The first track recorded 11 units, most of which were so broadly tuned that it was difficult to determine a CF. There did not appear to be a clear tonotopic sequence and, finally, a unit with a CF of $15.0 \mathrm{kHz}$ was marked, even though it was broadly tuned (Fig. 6A). It appeared that this track had transversed the external nucleus of IC. The second track entered IC more medially, and a clear tonotopic sequence was obtained. The first millimeter of the track contained 6 units which were too broadly responsive to tune (not shown on track). The next 22 units showed a fairly typical tonotopic sequence. The units were sharply tuned and had good thresholds (ranging from 6 to $43 \mathrm{~dB}$ ). The cell marked was an $E / l$ cell, but only one other $E / /$ was encountered on the track. Fourteen cells were $\mathrm{E} / \mathrm{O}$, and 3 were $\mathrm{E} / \mathrm{E}$. Two cells were ipsilateral dominant, being an $O / E$ and an $I / E$, respectively. The position of the blue spot coincided with the position of the reduced band of labeling (Fig. $6 B$ ), again indicating that the reduced or inhibitory contour was an isofrequency contour. In the sections shown, the inhibitory contour was about the same size as the excitatory one, but it became larger in more posterior sections (300 versus $400 \mu \mathrm{m}$ ). The inhibitory contour contained less label than the surrounding ICC, but it again contained more label than the background (Table IV). As before, both the excitatory and inhibitory bands appeared to extend into the lower levels of the dorsal cortex regions of IC (Oliver and Morest, 1984).

Crossed inhibition experiments. There is evidence that some cells in ICC have inhibitory sidebands to contralateral tones (Semple, 1981). To determine the organization of inhibitory sidebands in ICC, both tone bursts and white noise burst were given to the same ear. In animal $9,80 \mathrm{~dB}$ tones of $18.0 \mathrm{kHz}$ were presented with $50-\mathrm{dB}$ bursts of white noise to the left ear. In the right ICC, there was a dark band of labeling $(400 \mu \mathrm{m})$ and also a band of reduced labeling which was smaller $(300 \mu \mathrm{m})$ (Fig. $7 A)$. In this animal, the inhibitory band was smaller than the excitatory band throughout the nucleus, and neither the excitatory nor the inhibitory band became larger in more caudal sections. The reduced or inhibitory band was lateral to the increased band of labeling. Both the excitatory and the inhibitory bands were greater than the background level (Table V), but the inhibitory band contained significantly less label than the surrounding parts of the same ICC. It also contained more label than the opposite ICC (Table V). The excitatory band appears weaker than similar excitatory bands seen previously without concurrently presented white noise (Servière et al., 1984), probably due to peripheral masking (Moore, 1982).

In the last experimental animal, single unit recordings were made before the animal was tested for monaural inhibition. A typical tonotopic sequence of 14 units was recorded, and a unit with a CF of $9.2 \mathrm{kHz}$ was marked with pontamine sky blue. The first unit on the track was rather broadly tuned firing from 0.4 to $5.0 \mathrm{kHz}$. The following units were narrowly tuned and had low thresholds (ranging from -10 to $15 \mathrm{~dB}$ ). The animal was then presented with $80-\mathrm{dB}$ SPL tone bursts of $9.2 \mathrm{kHz}$ in conjunction with $80-\mathrm{dB}$ SPL white noise bursts. Once again, both a band of increased $(300 \mu \mathrm{m})$ and a band of decreased labeling $(250 \mu \mathrm{m})$ have been produced in the same ICC (Fig. 7C). The position of the blue spot coincided with the position of the excitatory band (Fig. 7C). Like the previous animal, the band of reduced labeling in this section was just smaller and more lateral than the band of increased labeling. The band of reduced labeling was sometimes larger in other sections ( 400 versus $350 \mu \mathrm{m}$ ) but did not increase in size in more caudal sections. Both

Figure 3. Montage of autoradiographs (left column) and photomicrographs of Nissl stains of the same sections (right column) showing both ICs in animal 5. White noise of $60 \mathrm{~dB}$ SPL was presented to the right ear, and a $15.0 \mathrm{kHz}$ tone of $80 \mathrm{~dB}$ SPL was presented to the left ear. In the right IC of each autoradiograph, there is a clear band of increased 2-DG labeling. In the left IC, there is a band of reduced labeling. The sections are arranged from caudal $(A)$ to rostral $(F)$. 
TABLE III

Uncrossed experiments without physiology

\begin{tabular}{|c|c|c|c|c|c|c|c|}
\hline \multirow{2}{*}{$\begin{array}{l}\text { Animal } \\
\text { No. }\end{array}$} & \multicolumn{2}{|c|}{ Stimulus Conditions } & \multicolumn{4}{|c|}{ Mean Densitometric } & \multirow[b]{2}{*}{$\rho$} \\
\hline & Left Ear & Right Ear & Comparisons & $\begin{array}{l}\text { Measures } \\
(\mu \mathrm{Ci} / \mathrm{gm})^{a}\end{array}$ & $t$ & $d f$ & \\
\hline 5 & $15.0 \mathrm{kHz}(80 \mathrm{~dB})$ & $W N^{b}(60 \mathrm{~dB})$ & $\mathrm{LICl}(15.0)$ vs. B & 146.6 vs. 27.9 & 107.6 & 264 & $<0.01$ \\
\hline 5 & $15.0 \mathrm{kHz}(80 \mathrm{~dB})$ & $W N(60 \mathrm{~dB})$ & LICl (15.0) vs. LICNI & 146.6 vs. 182.2 & 43.0 & 264 & $<0.01$ \\
\hline 5 & $15.0 \mathrm{kHz}(80 \mathrm{~dB})$ & $W N(60 \mathrm{~dB})$ & RICE (15.0) vs. B & 274.8 vs. 27.9 & 157.4 & 264 & $<0.01$ \\
\hline 6 & $W N(60 \mathrm{~dB})$ & $8.5 \mathrm{kH} \angle(50 \mathrm{~dB})$ & $\mathrm{RICl}(8.5)$ vs. B & 124.9 vs. 11.7 & 102.5 & 479 & $<0.01$ \\
\hline 6 & WN $(60 \mathrm{~dB})$ & $8.5 \mathrm{kHz}(50 \mathrm{~dB})$ & $\mathrm{RICl}(8.5)$ vs. RICNI & 124.9 vs. 143.5 & 24.6 & 479 & $<0.01$ \\
\hline 6 & $W N(60 \mathrm{~dB})$ & $8.5 \mathrm{kHz}(50 \mathrm{~dB})$ & LICE (8.5) vs. B & 135.9 vs. 11.7 & 123.2 & 479 & $<0.01$ \\
\hline 6 & WN $(60 \mathrm{~dB})$ & $15.9 \mathrm{kHz}(50 \mathrm{~dB})$ & LICE (15.9) vs. B & 143.7 vs. 11.7 & 141.6 & 479 & $<0.01$ \\
\hline
\end{tabular}

${ }^{a}$ All densitometric measures are as for Table II.

${ }^{b} \mathrm{WN}$, whitc noisc; $\mathrm{B}$, background; $\mathrm{LICl}$ or $\mathrm{RICl}$, left or right inferior colliculus inhibitory area; $\mathrm{LICNI}$ or RICNI, left or right inferior colliculus noninhibitory area; LICE or RICE, left or right inferior colliculus excitatory area.

the excitatory and inhibitory bands of labeling were significantly greater than background, and the inhibitory band contained less label than surrounding areas of the same ICC (Table V). The inhibitory band also contained more label than the corresponding area in the opposite ICC (Table V), and the excitatory band was also weaker than cormparable bands produced without while roise given to the same ear (Servière et al., 1984).

The monaural inhibitory bands in each animal were only present in the autoradiographs when a clear excitatory band was present. In each animal, both the excitatory and the inhibitory bands appeared to extend into the dorsal cortex regions of $\mathrm{IC}$.

\section{Discussion}

The experimental paradigm of presenting tones in conjunction with white noise has allowed us to reveal inhibitory as well as excitatory effects under 2-DG in the inferior colliculus of the cat. We started with the basic hypothesis that we were not finding inhibitory effects with 2-DG because of two factors: (1) that excitatory effects of $E / E$ and $E / O$ units did not allow smaller inhibitory reductions of 2 DG labeling to be distingluished; ( 2 ) that in these areas we were not able to detect a reduction of labeling through inhibition because of a lack of spontaneous activity. Thus, white noise was used to increase the overall background activity, a somewhat similar procedure having been successful in the visual system.

Uncrossed inhibitory effects. It is clear that presenting tone bursts to one ear and white noise bursts to the other ear has allowed us to discover areas of reduced labeling in the ICC ipsilateral to the ear receiving the tones. Although we have described these reductions as being binaural inhibitory effects, it is true that we have no direct evidence that there is an inhibitory process present. We concede this point, but we note that similar inferences are often made on the basis of extracellular recordings, including the visual experiments upon which our experimental design has been based (Bishop et al., 1973). This is not, of course, a powerful rejoinder, but if one accepts the logic of Sokoloff's 2-DG method (Sokoloff, 1977, 1982), then there has been a clear reduction of metabolic activity in these particular brain areas compared with areas activated only by white noise. There is little available evidence to suggest where this reduction or inhibition of activity is generated. The limited intracellular data (Nelson and Erulker, 1963; Kuwada et al., 1980) indicates that some cells can be hyperpolarized by input from one ear. These observations, coupled with the finding of Rockel and Jones (1973b) of inhibitory synapes on principal cclls of ICC, indicate a possible intrinsic inhibitory mechanism. The simplest hypothesis is, however, that it is not inhibition in ICC at all, but a reduction in activity to ICC by inhibition acting in the lateral superior olive (LSO). That is, it is suppression of afferent activity from LSO that is leading to reduced labeling in ICC (Nudo and Masterton, 1984). But it is known that LSO does not project to all the areas of IC through which the reduced bands extend (Glendenning and Masterton, 1983; Masterton and Imig, 1984). Furthermore, there is evidence that ICC receives major ascending projections from nine distinct brain stem regions and minor projections from at least four others (Roth et al., 1978; Adams, 1979). Thus, each lamina of ICC must receive multiple ascending input. It could hardly be argued that all of the inputs would provide suppression of afferent activity, as most of them do not have the binaural inhibitory properties found in LSO. The extent of the present inhibitory contours suggests, to us, a hypothesis of widespread intrinsic inhibition being the inhibitory source. It is apparent that if it is eventually possible to obtain a solution to the problem of the origin of the present inhibitory effects, it might well depend on further development of the 2-DG method for cellular resolution (Des Rosiers, 1978) and its application to both ICC and possible sources of afferent input.

Extent of the uncrossed inhibitory bands. The extensions of the bands of reduced activity into dorsal regions of IC outside ICC is of great interest. While it is difficult to use Nissl materials to subdivide $1 \mathrm{C}$, if the bands are compared to the Golgi drawings of Oliver and Morest (1984), they are clearly extending outside ICC. This is particularly so in caudal sections, where the inhibitory bands are the widest. In our earlier experiments (Servière et al., 1984), we found that both high- and low-frequency excitatory bands extended into DC and DM. This was very clearly seen with bands produced by lower-frequency tones. While these data indicate that the tonotopic organization of IC extends into these regions, the present data are the first to suggest that a similar inhibitory organization might do the same. There is increasing evidence (Brunso-Bechtold et al., 1981; Glendenning and Masterton, 1983; Oliver, 1984) that lemniscal input can reach further into these dorsal regions of IC than was thought previously (Goldberg and Moore, 1967; Kudo and Niimi, 1980; Kudo, 1981; Henkel and Spangler, 1983). A cochleotopic organization of lemniscal input has been revealed in dorsal regions of $I C$ by an extensive HRP study (Brunso-Bechtold et al., 1981). Recently, Oliver (1984) has shown strong projections from cochlear nucleus which reach as far as layer 3 of the dorsal cortex of IC.

Isofrequency uncrossed inhibitory contours. In earlier experiments (Servière et al., 1984), we have shown that excitatory bands produced in ICC under 2-DG are functional excitatory isofrequency contours. Anatomists using Golgi material have suggested that the structural basis of isofrequency contours in ICC are laminae consisting of the principal cells, their dendrites, and the incoming afferents (Rockel and Jones, 1973a, c; Oliver and Morest, 1984). The concept of a lamina has, however, been largely a theoretical concept until the recent 2-DG studies gave it such strong support (Servière et al., 1984; Webster et al., 1984a). The smallest width of some 2-DG excitatory contours found in these earlier studies (200 to $300 \mu \mathrm{m}$ ) indicated that they could be composed of 2 or 3 overlapping laminae, in agreement with estimates of laminae width 

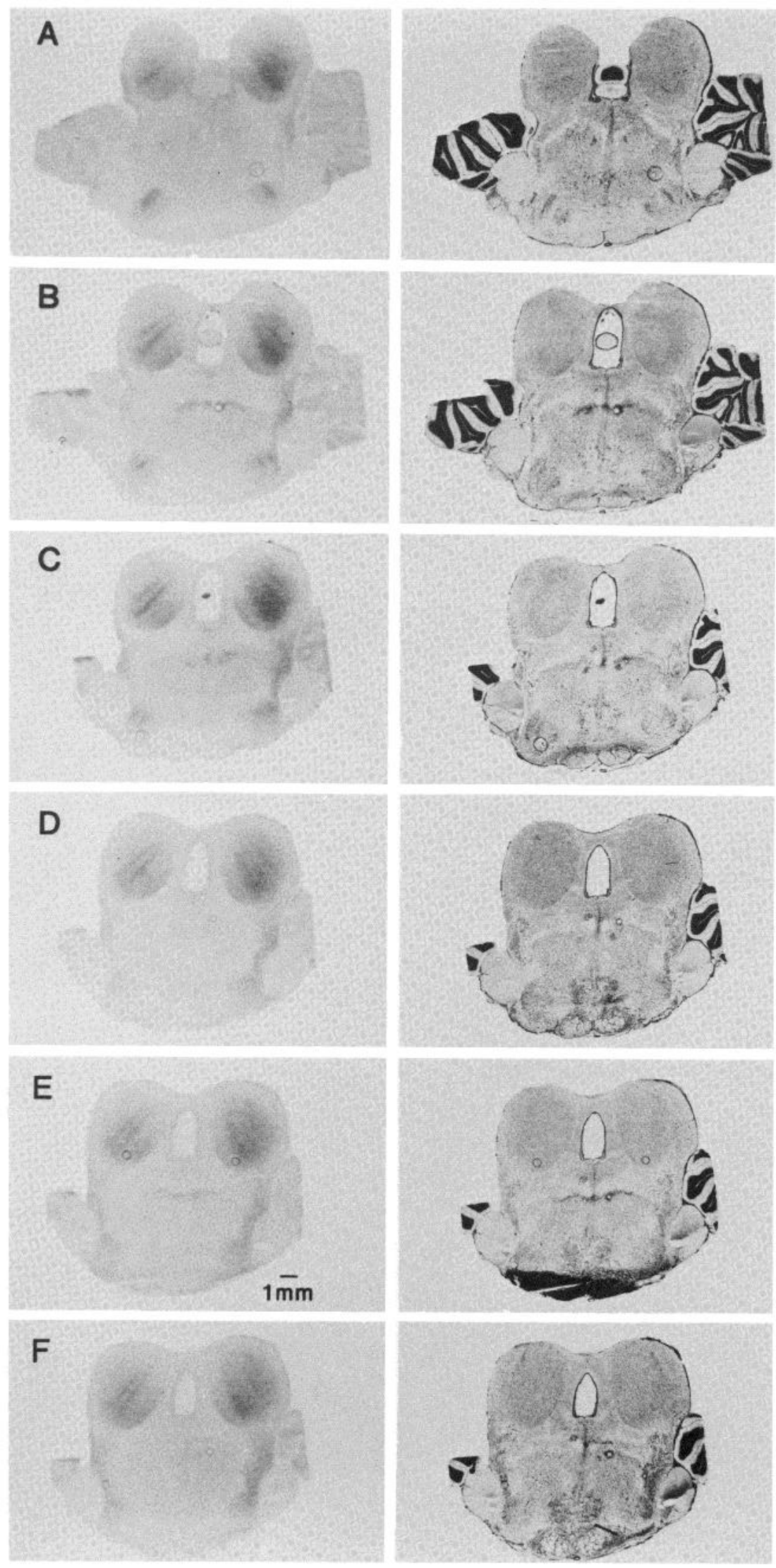
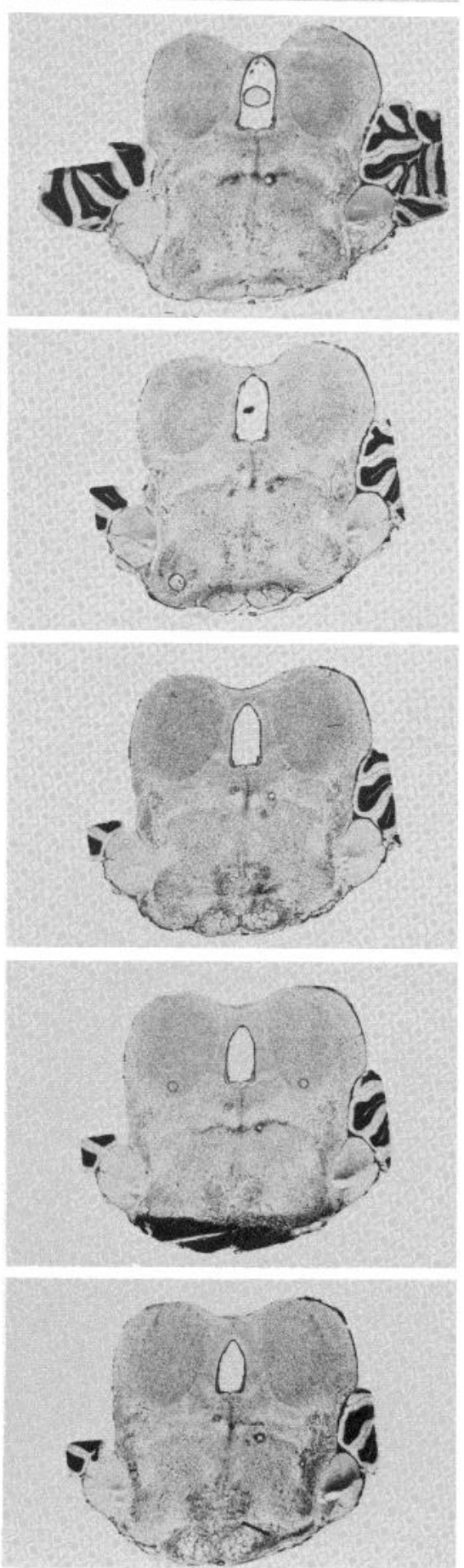

Figure 4. Montage of autoradiographs (left column) and photomicrographs of Nissl stains of the same sections (right column) showing both ICs in animal 6. This animal received $50-\mathrm{dB}$ SPL tone bursts of 8.5 and $15.9 \mathrm{kHz}$ in the right ear and 60-dB SPL white noise bursts in the left ear. Two bands of increased 2-DG labeling are seen in the left $\mathrm{IC}$, and two bands of reduced labeling are seen in the right IC. The sections are arranged from caudal $(A)$ to rostral $(F)$. 

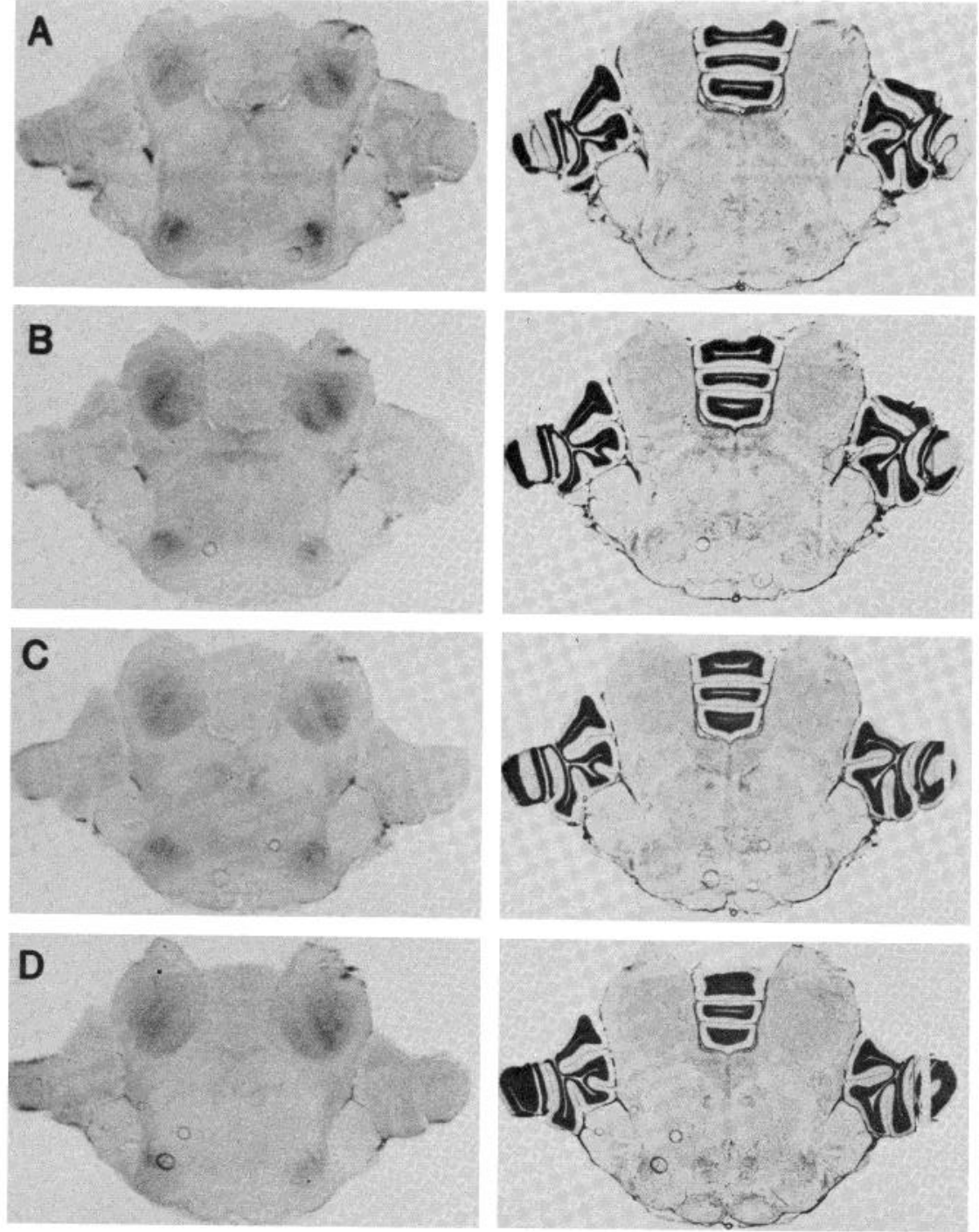

kHz
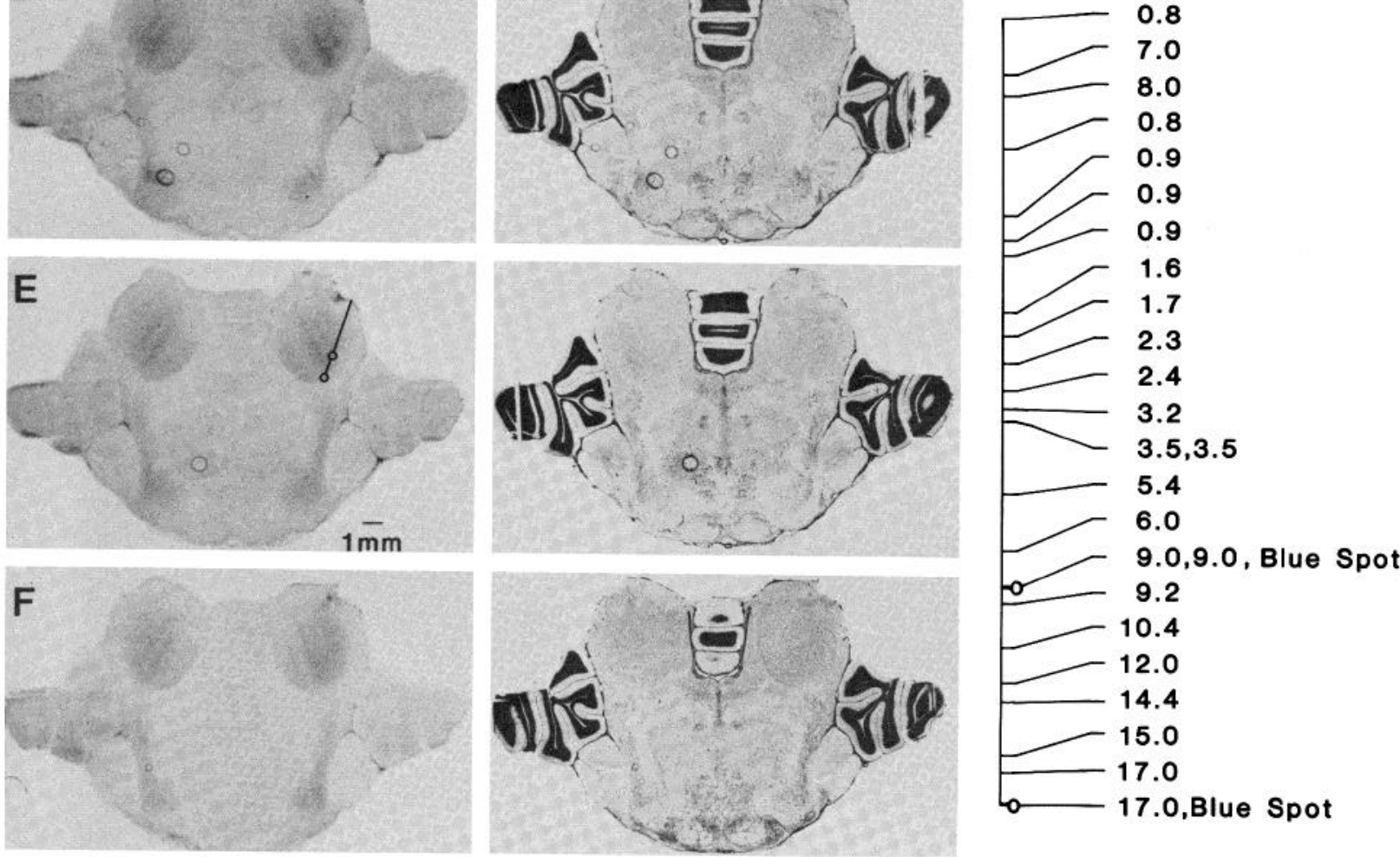

Figure 5. Montage of autoradiographs (left column) and photomicrographs of Nissl stains of the same sections (right column) showing both ICs in animal 7. This animal received $80-\mathrm{dB}$ SPL tone bursts of 9.0 and $17.0 \mathrm{kHz}$ in the right ear and $60 \mathrm{~dB}$ SPL white noise bursts in the left ear. Two bands of increased 2-DG labeling are seen in the left IC, and two bands of reduced labeling are seen in the right IC. An electrode track is superimposed on the autoradiograph in $E$, and the sequence of CFs and blue spots is shown on the right. The position of the blue spots are indicated by circles on the electrode track. The sections are arranged from caudal $(A)$ to rostral $(F)$. 
TABLE IV

Uncrossed experiments with physiology

\begin{tabular}{|c|c|c|c|c|c|c|c|}
\hline \multirow{2}{*}{$\begin{array}{l}\text { Animal } \\
\text { No. }\end{array}$} & \multicolumn{2}{|c|}{ Stimulus Conditions } & \multirow{2}{*}{ Comparisons } & \multirow{2}{*}{$\begin{array}{c}\text { Mean Densitometric } \\
\text { Measures } \\
(\mu \mathrm{Ci} / \mathrm{gm})^{\mathrm{a}}\end{array}$} & \multirow{2}{*}{$t$} & \multirow{2}{*}{$d f$} & \multirow{2}{*}{$p$} \\
\hline & Left Ear & Right Ear & & & & & \\
\hline 7 & $W N^{b}(60 \mathrm{~dB})$ & $17.0 \mathrm{kHz}(80 \mathrm{~dB})$ & $\mathrm{RICl}(17.0)$ vs. B & 108.2 vs. 12.7 & 116.7 & 207 & $<0.01$ \\
\hline 7 & $\mathrm{WN}(60 \mathrm{~dB})$ & $17.0 \mathrm{kHz}(80 \mathrm{~dB})$ & LICE (17.0) vs. B & 154.3 vs. 12.7 & 125.6 & 207 & $<0.01$ \\
\hline 7 & WN $(60 \mathrm{~dB})$ & $9.0 \mathrm{kHz}(80 \mathrm{~dB})$ & $\mathrm{RICl}(9.0)$ vs. B & 150.6 vs. 12.7 & 53.1 & 207 & $<0.01$ \\
\hline 7 & $W N(60 \mathrm{~dB})$ & $9.0 \mathrm{kHz}(80 \mathrm{~dB})$ & $\mathrm{RICl}(9.0)$ vs. $\mathrm{RICNI}$ & 150.6 vs. 159.3 & 10.1 & 207 & $<0.01$ \\
\hline 7 & WN $(60 \mathrm{~dB})$ & $9.0 \mathrm{kHz}(80 \mathrm{~dB})$ & LICE (9.0) vs. B & 155.9 vs. 12.7 & 85.2 & 207 & $<0.01$ \\
\hline 8 & WN $(80 \mathrm{~dB})$ & $10.5 \mathrm{kHz}(80 \mathrm{~dB})$ & LICE (10.5) vs. B & 259.5 vs. 58.5 & 103.4 & 506 & $<0.01$ \\
\hline
\end{tabular}

${ }^{a}$ All densitometric measures are as for Table II.

${ }^{b} \mathrm{WN}$, white noise; $\mathrm{B}$, background; RICl, right inferior colliculus inhibitory area; RICNI, right inferior colliculus noninhibitory area; LICE, left inferior colliculus excitatory area.
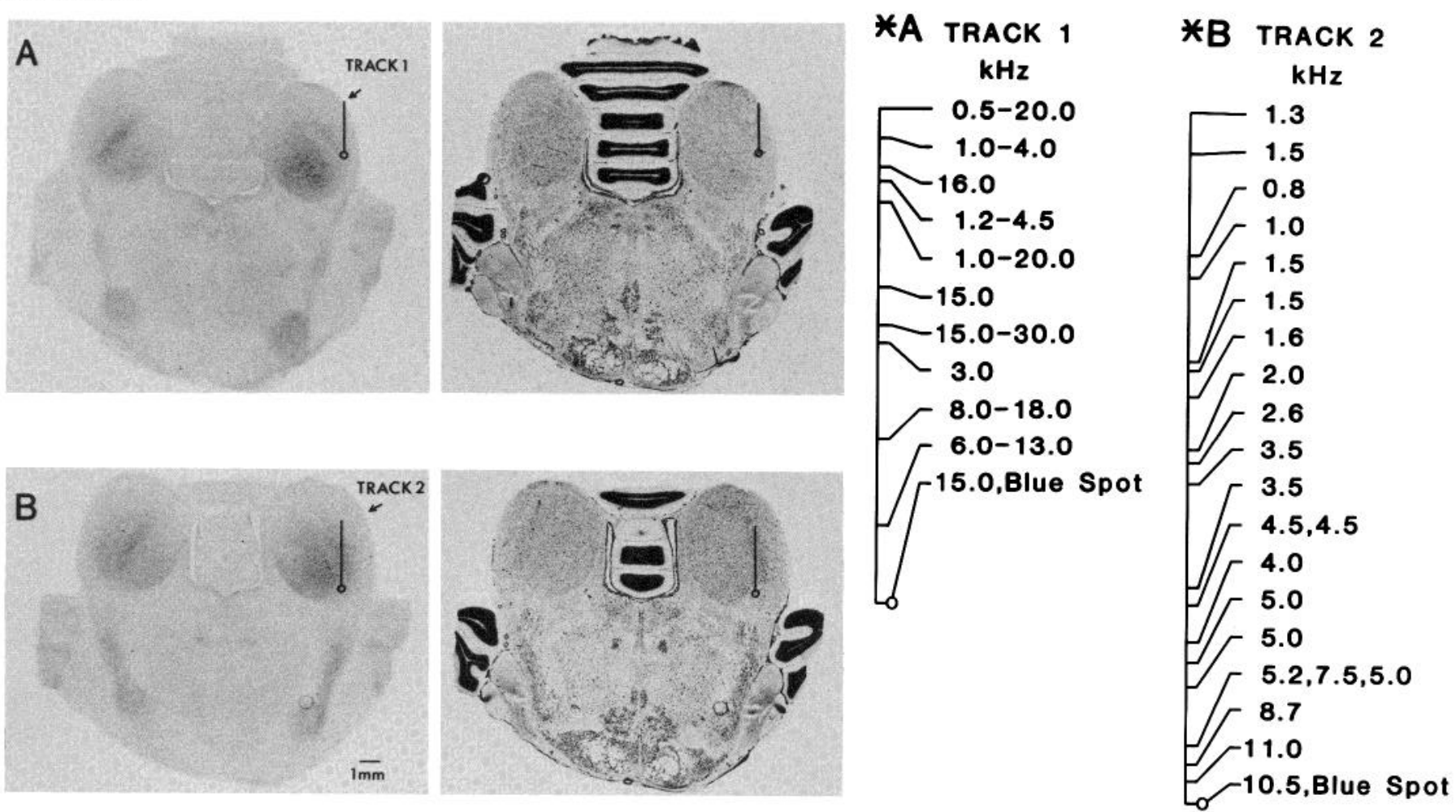

Figure 6. A and $B$, An autoradiograph (left) and a photomicrograph of a Nissl stain of the same sections (right) showing both ICs in animal 8. This animal received $80-\mathrm{dB}$ SPL tone bursts of $10.5 \mathrm{kHz}$ in the right ear and $80-\mathrm{dB}$ SPL white noise bursts in the left ear. In both $A$ and $B$, the autoradiographs show a band of increased labeling in the left IC and a band of reduced labeling in the right IC. In $A$, there is superimposed electrode track 1 , which contained broadly tuned cells and little tonotopic order. In $B$, there is superimposed electrode track 2 , which shows a tonotopic sequence. * $A$ and ${ }^{*} B$ illustrate the sequence of CFs of cells along each track. In track 1 , many cells could not be given a precise CF, and a range of frequencies are indicated. The position of a blue spot is indicated on each track by a small circle. The section in $A$ is more caudal than the section in $B$.

measured by Rockel and Jones (1973a). Many of our present excitatory bands are in close agreement with these results. In our earlier cat experiments, multiple electrode tracks were made, and the position of two units with the same CF was shown to coincide with each 2-DG contour produced by the particular frequency (Servière et al., 1984). Although two points are the minimum needed to define a two-dimensional isofrequency contour, we have extrapolated from the 2.DG data to argue that our 2.DG contours are sections through three-dimensional iso-frequency structures in ICC (some of our unpublished data show that the 2-DG excitatory contours can be observed in all three standard anatomical planes and are clearly three-dimensional sheets). On the basis of these earlier results, we have resorted in the present experiments to identifying isofrequency contours by the correlation of a single frequency point with the 2-DG contour. In the context of the earlier experiments, we feel it is reasonable to argue that the present uncrossed inhibitory effects are indications of functional isofrequency inhibitory contours.

Given the above arguments, it is clear that if the inhibitory contours are related to the laminar structure of ICC, they are involving more laminae than the corresponding excitatory processes, since the isofrequency inhibitory contours are generally wider. However, the extension of the contours into DC raise some problems, as the fibrodendritic laminae do not appear to extend into this region. This was also a problem for our previous excitatory contours (Servière et al., 1984) but, in both cases, the results suggest a precise ordering of lemniscal input without the presence of laminae.

Crossed inhibitory effects. Clear crossed inhibitory effects are seen in the present experiments which are demonstrably related to the frequency of the tone presented with white noise to the same 

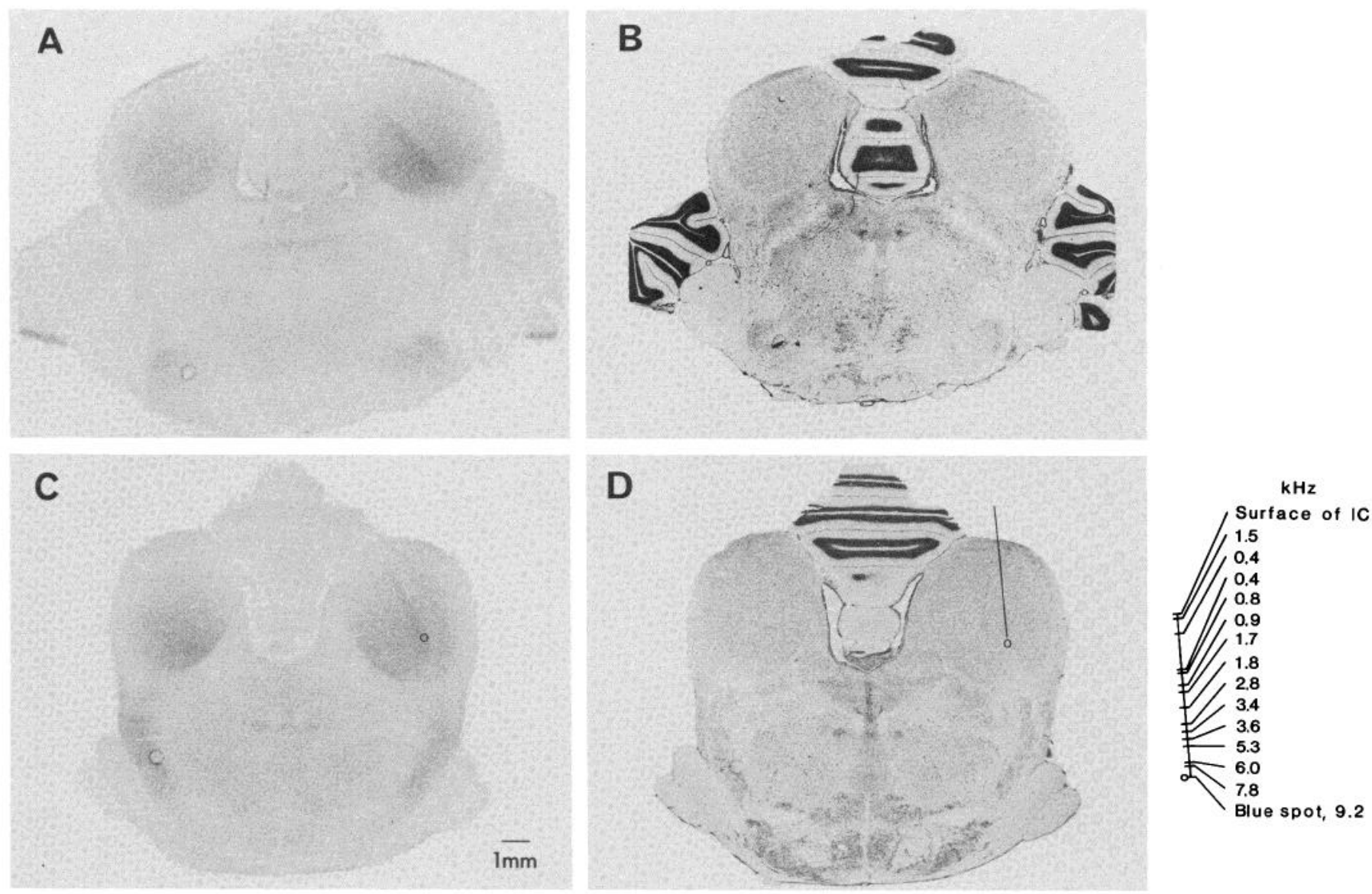

Figure 7. A, An autoradiograph of a section through both ICs of animal 9. This animal received 80-dB SPL 18.0-kHz tone bursts through the left ear concurrently with 50-dB SPL bursts of white noise. In the right IC of $A$, there is a band of increased labeling, and lateral to this is a band of reduced labeling. $B$, A photomicrograph of a Nissl stain of the same section. C, An autoradiograph of a section through both ICs of animal 10 . This animal received 80 -dB SPL 9.2-kHz tone bursts through the left ear concurrently with 50-dB SPL bursts of white noise. There is a band of increased labeling in the right IC, and lateral to this a band of reduced labeling. $D$, A photomicrograph of a Nissl stain of the same section. An electrode track is superimposed on $D$, and alongside is presented the tonotopic sequence of CFs recorded. The position of a blue spot is indicated by a small circle in both $C$ and $D$.

TABLE V

Crossed experiments

\begin{tabular}{|c|c|c|c|c|c|c|c|}
\hline \multirow{2}{*}{$\begin{array}{l}\text { Animal } \\
\text { No. }\end{array}$} & \multicolumn{2}{|c|}{ Stimulus Conditions } & \multirow{2}{*}{ Comparisons } & \multirow{2}{*}{$\begin{array}{c}\text { Mean Densitometric } \\
\text { Measures } \\
(\mu \mathrm{Cl} / \mathrm{gm})^{a}\end{array}$} & \multirow{2}{*}{$t$} & \multirow{2}{*}{$d f$} & \multirow{2}{*}{$p$} \\
\hline & Left Ear & Right Ear & & & & & \\
\hline 9 & $\begin{array}{c}18.0 \mathrm{kHz}(80 \mathrm{~dB}) \\
\mathrm{WN}^{\circ}(50 \mathrm{~dB})\end{array}$ & No stimulus & $\mathrm{RICl}$ vs. B & 130.5 vs. 56.6 & 71.25 & 63 & $<0.01$ \\
\hline 9 & $\begin{array}{c}18.0 \mathrm{kHz}(80 \mathrm{~dB}) \\
\text { WN }(50 \mathrm{~dB})\end{array}$ & No stimulus & $\mathrm{RICl}$ vs. RICNI & 130.5 vs. 140.2 & 13.14 & 63 & $<0.01$ \\
\hline 9 & $\begin{array}{c}18.0 \mathrm{kHz}(80 \mathrm{~dB}) \\
\text { WN }(50 \mathrm{~dB})\end{array}$ & No stimulus & RICE vs. B & 156.3 vs. 56.6 & 104.6 & 63 & $<0.01$ \\
\hline 9 & $\begin{array}{c}18.0 \mathrm{kHz}(80 \mathrm{~dB}) \\
\text { WN }(50 \mathrm{~dB})\end{array}$ & No stimulus & RICNI vs. LICNI & 140.2 vs. 113.0 & 22.6 & 63 & $<0.01$ \\
\hline 10 & $\begin{array}{c}9.0 \mathrm{kHz}(80 \mathrm{~dB}) \\
\mathrm{WN}(80 \mathrm{~dB})\end{array}$ & No stimulus & $\mathrm{RICl}$ vs. B & 108.6 vs. 82.6 & 26.45 & 63 & $<0.01$ \\
\hline 10 & $\begin{array}{l}9.0 \mathrm{kHz}(80 \mathrm{~dB}) \\
\mathrm{WN}(80 \mathrm{~dB})\end{array}$ & No stimulus & $\mathrm{RICl}$ vs. RICNI & 108.6 vs. 114.3 & 7.84 & 63 & $<0.01$ \\
\hline 10 & $\begin{array}{l}9.0 \mathrm{kHz}(80 \mathrm{~dB}) \\
\mathrm{WN}(80 \mathrm{~dB})\end{array}$ & No stimulus & RICE vs. B & 123.0 vs. 82.6 & 29.15 & 63 & $<0.01$ \\
\hline 10 & $\begin{array}{l}9.0 \mathrm{kHz}(80 \mathrm{~dB}) \\
\mathrm{WN}(80 \mathrm{~dB})\end{array}$ & No stimulus & RICNI vs. LICNI & 114.3 vs. 100.7 & 9.3 & 63 & $<0.01$ \\
\hline
\end{tabular}

${ }^{a}$ All densitometric measures are as for Table II.

${ }^{\circ}$ WN, white noise; B, background; RICl, right inferior colliculus inhibitory area; RICNI or LICNI, right or left inferior colliculus noninhibitory area; RICE, right inferior colliculus excitatory area. 
ear. The results of animal 10 show a clear correlation between the position of a unit with a CF of $9.2 \mathrm{kHz}$ and the excitatory band produced by tones of $9.2 \mathrm{kHz}$ (Fig. $7, C$ and $D$ ). In animal 9 , the position of the excitatory band to $18.0-\mathrm{kHz}$ tone bursts is more medial than the band to the $9.2-\mathrm{kHz}$ tone bursts (Fig. 7, $A$ and $B$ ), as would be predicted from our earlier work (Servière et al., 1984). In each case, the inhibitory band is found laterally alongside the excitatory band and its position moved as the position of the excitatory band moved with change in frequency. It would be a reasonable extrapolation to say that these inhibitory bands are also isofrequency contours. The question again arises as to just what mechanism is producing the reduction or inhibition.

Since we are giving the tone and the white noise simultaneously to the one cochlea, it is possible that some cochlear mechanism, such as two-tone inhibition, could be producing suppression (Evans, 1975). However, we don't appear to have 2-DG inhibition present at the level of the cochlear nucleus $(\mathrm{CN})$, which makes a cochlear explanation a little unlikely. We temper this conclusion by pointing out that the sirlall sice of dorsal cochlear nucleus (DCN) and of the ventral cochlear nucleus (VCN) compared with ICC might make detection of small inhibitory areas quite difficult, even with our methods of analysis. It is also possible that, like the binaural effects, this inhibition is generated outside IC but more centrally from the cochlea.

Another possibility is that we are seeing some form of sideband inhibition which is generated within ICC. It has been shown that many units are inhibited as well as excited by tone stimulation in the awake cat using free field conditions (Bock et al., 1972), and sidebands are present in some $1 \mathrm{CC}$ units in the anesthetized cat using sealed stimulation conditions (Rose et al., 1963; Semple, 1981). However, very few units have been analyzed in detail for monaural sidebands in anesthetized animals, and there is thus no real evidence about the exact proportions of cells with monaural low- and/or high-frequency sidebands. If one accepts the argument that the contours observed are produced by sideband inhibition, then several difficult issues arise. First, which cells are producing the inhibitory sideband? Second, why do we see only an apparently low-frequency sideband relative to the stimulating tone? The sideband inhibition cannot arise from the cells which are producing the excitatory band, as these cells have excitatory CFS either at the stimulating frequency or very close to it. It is possible that there is also a large population of cells with their excitatory fields entirely surrounded by inhibition (Young and Brownell, 1976). Such cells might be able to produce the inhibition at the intensity levels used in these experiments ( $80 \mathrm{~dB}$ SPL), but such a population has not yet been reported for ICC (Semple, 1981).

We would argue that if the inhibitory band represents sideband inhibition, then it could come from cells which have excitatory CFs below the frequency activating the inhibition. That is, we are seeing the expression of high-frequency sidebands of such a group of cells. If the logic of this argument is correct, then it raises the question of why the tone does not also activate a more medial inhibitory band which could represent the low-frequency sidebands of units with CFs higher than the activating tone. Some possible explanations of these results are that either low-frequency sidebands might not be strong enough to be detected, or they could be overlaid by a lowfrequency excitatory tail. There is no critical evidence for the first possibility, but some ICC units with low-frequency sidebands also have a low-frequency excitatory tail above the inhibition (Semple, 1981). Thus stimulation of these areas by sufficiently strong stimuli would most likely produce a net excitatory effect. Obviously, further experiments are needed with less intense tone stimuli which might only activate the low-frequency inhibitory sidebands of such cells.

One final possibility is that the presence of barbiturate anesthetic is selectively reducing the effects of low-frequency sidebands. There is some evidence that this anesthetic can change the inhibitory/ excitatory relationships of a cell (Young and Brownell, 1976). However, physiological data are not available for ICC to decide this point.

\section{Conclusions}

For the first time with the 2-DG technique, our experimental paradigm of increasing the background activity in a sensory system has allowed us to reveal two forms of inhibition which can be correlated with single unit activity in the same animal. Unlike higher auditory centres, the $\mathrm{IC}$ appears to contain a binaural $(E / I)$ system of inhibition that parallels the isofrequency system rather than being orthogonal to it. The results show the power of the 2-DG method, as it is difficult to see how any other technique could have allowed us to see the width and extent of this binaural system.

Our technique has also allowed us to see monaural inthibition, which could be regarded as sideband or lateral inhibition. This inhibition is quite clear, but it did not became wider in more caudal regions of $\mathrm{IC}$ as did the binaural bands. Further experiments are needed to determine whether a low-frequency sideband mechanism can be revealed. Overall, the general paradigm used in these experiments might have considerable application to the 2-DG studies of other sensory systems and help to reveal hitherto unknown inhibitory mechanisms.

\section{References}

Adams, J. C. (1979) Ascending projections to the inferior colliculus. J. Comp. Neurol. 183: 519-538

Aitkin, L. M., W. R. Webster, J. L. Veale, and D. C. Crosby (1975) Inferior colliculus. I. Comparison of properties of neurons in central, pericentral and external nucleus of the cat. J. Neurophysiol. 38: 11961207.

Bishop, P. O., J. S. Coombs, G. H. Henry (1973) Receptive fields of simple cells in the cat striate cortex. J. Physiol. (Lond.) 231: 31-60.

Boakes, R. J., G. J. Bramwell, I. Briggs, J. M. Candy, and E. Temperla (1974) Localization with pontamine sky blue of neurons in the brainstem responding to microiontophoretically applied compounds. Neuropharmacol. 13: $4 / 5-4 / 9$

Bock, G. R., and W. R. Webster (1974a) Coding of spatial location by single units in the inferior colliculus of the alert cat. Exp. Brain Res. 21: 387-398.

Bock, G. R., and W. R. Webster (1974b) Spontaneous activity of single units in the inferior colliculus of anesthetized and unanesthetized cats. Brain Res. 76: 150-154.

Bock, G. R., W. R. Webster, and L. M. Aitkin (1972) Discharge patterns of single units in inferior colliculus of the alert cat. J. Neurophysiol. 35: 265277.

Brunso-Bechtold, J. K., G. C. Thompson, and R. B. Masterton (1981) HRP study of the organization of auditory afferents ascending to central nucleus of the inferior colliculus in cat. J. Comp. Neurol. 197: 704-722.

Calford, M. B., and W. R. Webster (1981) The auditory representation within the principal division of the cat medial geniculate body: An electrophysiological study. J. Neurophysiol. 45: 1013-1028.

Des Rosiers, M. H., and L. Descarries (1978) Adaptation de la méthode au désoxyglucose à l'échelle cellulaire: Préparation histologique du système nerveux central en vue de la radioautographie à haute résolution. $C$. $R$. Acad. Sci. Ser. D 287: 153-156.

Evans, E. F. (1975) Cochlear nerve and cochlear nucleus. in. Handbook of Sensory Physiology, W. D. Keidel and W. D. Neff, eds., Vol. V, Part 2, pp. 1-108, Springer-Verlag, New York.

Gallistel, C. R., C. T. Piner, T. O. Allen, N. T. Adler, E. Yadin, and M. Negin (1982) Computer assisted analysis of 2-DG autoradiographs. Neurosci. Behav. Rev. 6: 409-420.

Glendenning, K. K., and R. B. Masterton (1983) Acoustic chiasm: Efferent projections of the lateral superior olive. J. Neurosci. 3: 1521-1537.

Goldberg, J. M., and R. Y. Moore (1967) Ascending projections of the lateral lemniscus in the cat and monkey. J. Comp. Neurol. 129: 143-156.

Goochee, C., W. Rasband, and L. Sokoloff (1980) Computerized densitometry and colour coding of $\left[{ }^{14} \mathrm{C}\right]$-deoxyglucose autoradiographs. Ann. Neurol. 7: 359-370.

Henkel, C. K., and K. M. Spangler (1983) Organization of the efferent projections of the medial superior olivary nucleus in the cat as revealed by HRP and autoradiographic tracing methods. J. Comp. Neurol. 221: 416428.

Imig, T. J., and H. O. Adrian (1977) Binaural columns in the primary field (A1) of cat auditory cortex. Brain Res. 138: 241-257. 
Imig, T. J., and J. F. Brugge (1978) Sources and terminations of callosal axons related to binaural and frequency maps in primary auditory cortex of the cat. J. Comp. Neurol. 182: 637-660.

Imig. T. J., and R. A. Reale (1981) Patterns of cortico-cortical projections related to binaural columns in cat primary auditory cortex. J. Comp. Neurol. 203: 1-14.

Kudo, M. (1981) Projections of the nuclei of the lateral lemniscus in the cat: An autoradiographic study. Brain Res. 221: 57-69.

Kudo, M., and K. Niimi (1980) Ascending projections of the inferior colliculus in the cat: An autoradingraphic study. .1. Comp. Neurol. 191: 545-553.

Kuwada, S., T. C. T. Yin, L. B. Haberly, and R. E. Wichesberg (1980) Binaura interaction in the cat inferior colliculus: Physiology and anatomy. In Psy chophysical, Physiological, and Behavioural Studies in Hearing, G. Van den Brink and F. A. Bilsen, eds., pp. 401-411, Delft University Press, Delft.

Lee, B. G., G. Mandl, and P. B. Stean (1969) Microelectrode tip position marking in nervous tissue. A new dye method. Electroencephalogr. Clin. Neurophysiol. 27: 610 613.

Masterton, R. B., and T. J. Imig (1984) Neural mechanisms for sound localization. Annu. Kev. Mhysiol. 46: 275-287.

Middlebrooks, J. C., and J. M. Zook (1983) Intrinsic organization of the cat's medial geniculate body identified by projections to binaural responsespecific bands in the primary auditory cortex. J. Neurosci. 3: 203-224.

Middlebrooks, J. C., R. W. Dykes, and M. M. Merzenich (1980) Binaural response specific bands in the primary auditory cortex (A1) of the cat: Topographical organization orthogonal to isofrequency contours. Brain Res. 181: 31-48

Moore, B. C. J. (1982) An Introduction to the Psychology of Hearing, Academic Press, Inc., New York.

Nelson, P. G., and S. D. Erulkar (1963) Synaptic mechanisms of excitation and inhibition in the central auditory pathway. J. Neurophysiol. 26: 908923.

Nudo, R. J., and R. B. Masterton (1984) 2-Deoxyglucose studies of stimulus coding in the brainstem auditory system of the cat. In Contribution to Sensory Physiology, W. D. Neff, ed., pp. 79-97, Academic Press, New York.

Oliver, D. L. (1984) Dorsal cochlear nucleus projections to the inferior colliculus in the cat: A light and electron microscopic study. J. Comp. Neurol. 224: $155-172$.

Oliver, D. L., and D. K. Morest (1984) The central nucleus of the inferior colliculus in the cat. J. Comp. Neurol. 222: 237-264.

Rockel, A. J., and E. G. Jones (1973a) The neural organization of the inferior colliculus of the cat. I. The central nucleus. J. Comp. Neurol. 147: 11-60
Rockel, A. J., and E. G. Jones (1973b) Observations on the fine structure of the central nucleus of the inlerior colliculus of the cat. J. Comp. Neurol. 26: $61-92$

Rockel, A. J., and E. G. Jones (1973c) The neural organization of the inferior colliculus in the cat. II. The pericentral nucleus. J. Comp. Neurol. 149 301-334.

Rose, J. E., D. D. Greenwood, J. M. Goldberg, and J. E. Hind (1963) Some discharge characteristics of single neurons in the inferior colliculus of the cat. I. Tonotopic organization, relation of spike counts to intensity, and firing patterns of single elements. I. Neurophysinl. 26: 294-320

Roth, G. L., L. M. Aitkin, R. A. Andersen, and M. M. Merzenich (1978) Some features of the spatial organization of the central nucleus of the inferio colliculus of the cat. J. Comp. Neurol. 182: 661-680.

Semple, M. N. (1981) Organization of the central nucleus of the cat inferior colliculus: Single unit response properties and ascending afferent projections. Ph.D. thesis, Monash University, Clayton, Australia.

Semple, M. N., and L. M. Aitkin (1979) Representation of sound frequency and laterality by units in central nucleus of the cat inferior colliculus. $J$. Neurophysiol. 42: 1626-1639.

Servière, J., W. R. Webster, and M. B. Calford (1984) Iso-frequency labelling revealed by a combined $2-\left[{ }^{14} \mathrm{C}\right]$-deoxyglucose, electophysiological, and horseradish peroxidase study of the inferior collicullus of the cat. J. Comp. Neurol. 228: 463-477.

Sharp. F. R., T. S. Kilduff, S. Bzorgchami, H. C. Heller, and A. F. Ryan. (1983) The relationship of local cerebral glucose utilization to optical density ratios. Brain Res. 263: 97-103.

Sokoloft, L. (1977) Relation between physiological function and energy in the central nervous system. J. Neurochem. 29: 13-26.

Sokoloff, L. (1982) The radioactive deoxyglucose method. In Advances in Neurochemistry, B. W. Agranoff and M. 11. Aprison, eds., pp. 1-82, Plenum, New York.

Webster, W. R., J. Servière, D. Crewther, and S. Crewther (1984a) Isofrequency contours in the inferior colliculus of the awake monkey. Exp Brain Res. 56: 425-437.

Webster, W. R., J. Servière, and M. Brown (1984b) Inhibitory contours in the inferior colliculus as revealed by the 2-deoxyglucose method. Exp. Brain Res. 56: 577-581.

Winer, B. J. (1970) Statistical Principles in Experimental Design. McGrawHill, New York.

Young, E. D., and W. E. Brownell (1976) Responses to tones and noise of single cells in dorsal cochlear nucleus of unanesthetized cats. J. Neurophysiol. 39: 282-300 